\title{
HIV Testing in Urban Transgender Individuals: A Descriptive Study
}

\author{
Adrian Juarez-Cuellar ${ }^{*}$ and Yu-Ping Chang
}

\begin{abstract}
HIV testing is considered the initial component of HIV eradication strategies. This study aimed to describe HIV testing in urban, transgender individuals in western New York. The study uses HIV testing intake data from a sample of self-identified transgender males and females volunteering for an HIV test at a community-based healthcare organization. Transgender individuals with some characteristics were found to have more HIV tests including female gender, black, HIV status (positive), a history of incarceration, sex worker, housing situation, and self-referral. The findings can be used to tailor future interventions to encourage HIV testing in transgender populations.
\end{abstract}

Keywords: health disparity; HIV testing; substance abuse; transgender

\section{Introduction}

The transgender community experiences numerous access barriers to care, such as perceived social discrimination or limited clinical knowledge by care providers regarding transgender health needs. ${ }^{1-4}$ Although there are no national databases regarding the HIV burden in the transgender population, there is a small body of literature that confirms additional HIV burden and poorer outcomes in the transgender male to female population. ${ }^{3,5,6}$ Transgendered individuals experience additional disparities as compared with other LGBT subgroups, including socioeconomic discrepancies, access barriers, increased risk behaviors, increased stigmatization, higher rates of self-perceived discrimination, physical violence, depression, suicide, substance abuse, prostitution, homelessness, and lack of financial support. ${ }^{2,3,5,7-14}$ For trans women of color, HIV disparities include having a higher rate of HIV infection and higher AIDS-related mortality than white trans women. ${ }^{4,15,16}$

Current HIV science and treatment strategies such as "treatment as prevention" propose that HIV can be eradicated using "seek, test, treat, and retain" (STTR) models. ${ }^{17-19}$ The goal of these STTR models is to ensure that HIV negative populations remain negative and that HIV positive populations achieve a "un- detectable" viral load and are thereby unable to transmit the HIV. STTR has been successful in several populations, ${ }^{18-20}$ but there remains an evidence gap regarding the feasibility of STTR intervention in transgender communities.

Existing evidence regarding transgender HIV testing is limited to identified HIV testing factors. Known HIV testing factors associated with the transgender identity include knowledge level regarding HIV and/or AIDS, sex with sex workers, spousal communication about HIV, education level, socioeconomic status, and proximity of HIV testing. ${ }^{6,21,22}$ The purpose of this study is to describe HIV and other sexually transmitted disease (STD) testing in urban transgender individuals.

\section{Methods}

Participants

Inclusion criteria for all potential subjects entailed selfidentification as a transgender man or transgender woman, consenting to an HIV test and an intake interview at the collaborating organization. The only exclusion criterion is that the subjects must be over the age of 18. Subjects with more than one HIV test were analyzed based on data at the time of first visit.

School of Nursing, The State University of New York, University at Buffalo, Buffalo, New York.

*Address correspondence to: Adrian Juarez, PhD, RN, School of Nursing, The State University of New York, University at Buffalo, 3435 Main Street, Wende Hall Room 201F, Buffalo, NY 14214, E-mail: juarezad@buffalo.edu

(c) Adrian Juarez-Cuellar and Yu-Ping Chang 2017; Published by Mary Ann Liebert, Inc. This is an Open Access article distributed under the terms of the Creative Commons Attribution License, which permits unrestricted use, distribution, and reproduction in any medium, provided the original work is properly cited. 
Study design

This study used secondary data analysis to evaluate existing HIV testing survey data that were collected at the collaborating organization before an individual's HIV test. Our collaborating organization is located in an urban area and provides free HIV and STD tests. Data were deidentified and then sent to the research team. Surveys were collected for the New York State AIDS Institute Reporting System (AIRS) from 2007 to May 2013. Data collected included demographics, HIV testing history, perceived HIV risks, and associated HIV care, such as antiretroviral history. Protection of a subject's HIV status was ensured throughout this secondary data analysis. Any identifying information was removed by the collaborating organization. All individuals were assigned unique identification numbers. After IRB approval, initial data processing and cleaning techniques were performed. Descriptive statistics were used for data analysis.

\section{Measures}

Surveys were collected by HIV testing technicians using a formatted survey packet that explained the HIV testing procedure and other items required by the New York State AIRS. Subjects volunteered information and had the option of not responding to survey items. The existing database consists of 27 variables. After data cleaning and elimination of variables with severe missing data, 12 variables were selected as potential correlates (independent variables) that might influence the number of tests for HIV and STD (dependent variables). These independent variables included age, gender, race, HIV status, history of substance abuse, sex partner, history of incarceration, sex worker, support group enrolled (different types of support group that participants were enrolled in the collaborating organization), insurance status, housing (living situation), and referral source.

\section{Results}

Data from 27 individuals were available for the purpose of the study. These individuals were self-identified transgender females $(n=23)$ and transgender males $(n=4$; Table 1$)$. The age of the participants ranged from 20 to 65 years, with a mean of 33 years (standard deviation $[S D]=13.3)$. The majority of the participants were white $(n=11,40.7 \%)$ and black/African American $(n=8,29.6 \%)$. More than half $(56 \%)$ of the participants $(n=15)$ had been incarcerated and about $56 \%$ of them $(n=15)$ were current sex workers. Approximately half
Table 1. Demographic Characteristics of Sample $(n=27)$

\begin{tabular}{|c|c|}
\hline \multicolumn{2}{|l|}{ Variables } \\
\hline Age, mean (SD) & 33.96 years (13.2), range: $20-65$ \\
\hline Number of HIV tests & Mean 3.11 , range: $1-10$ \\
\hline Number of STD tests & Mean 1.26 , range: $0-6$ \\
\hline \multicolumn{2}{|l|}{ Gender, $n(\%)$} \\
\hline Female & $23(85.2)$ \\
\hline Male & $4(14.8)$ \\
\hline \multicolumn{2}{|l|}{ Race, $n(\%)$} \\
\hline White & $11(40.7)$ \\
\hline Black & $8(29.6)$ \\
\hline Hispanic & $5(18.5)$ \\
\hline Unknown & $3(11.1)$ \\
\hline \multicolumn{2}{|l|}{ HIV status, $n(\%)$} \\
\hline Positive with AIDS diagnosis & $1(3.7)$ \\
\hline Positive without AIDS & $2(7.4)$ \\
\hline Negative at risk & $16(59.3)$ \\
\hline Negative & $8(29.6)$ \\
\hline \multicolumn{2}{|l|}{ Sex partner, $n(\%)$} \\
\hline Nonspecified or unknown & $10(37.0)$ \\
\hline Sex with male & $14(51.9)$ \\
\hline Sex with female & $2(7.4)$ \\
\hline Sex with both gender & $1(3.7)$ \\
\hline \multicolumn{2}{|l|}{ Incarcerated, $n$ (\%) } \\
\hline Yes & $15(55.6)$ \\
\hline No & $12(44.4)$ \\
\hline \multicolumn{2}{|l|}{ Sex work, $n(\%)$} \\
\hline Yes & $15(55.6)$ \\
\hline No & $12(44.4)$ \\
\hline \multicolumn{2}{|l|}{ History of substance abuse, $n(\%)$} \\
\hline Yes & $26(96.3)$ \\
\hline No & $1(3.7)$ \\
\hline \multicolumn{2}{|l|}{ Insurance, $n$ (\%) } \\
\hline Insured & $6(22.2)$ \\
\hline HIV uninsured care program & $1(3.7)$ \\
\hline Unknown & $20(74.1)$ \\
\hline \multicolumn{2}{|l|}{ Housing, $n(\%)$} \\
\hline Permanent housing rental & $20(74.1)$ \\
\hline With family or friend & $2(7.4)$ \\
\hline Residential drug treatment & $3(11.1)$ \\
\hline Transitional housing & $1(3.7)$ \\
\hline Homeless in shelter & $1(3.7)$ \\
\hline \multicolumn{2}{|l|}{ Referral source, $n(\%)$} \\
\hline Evergreen & $6(22.2)$ \\
\hline Friend/family & $5(18.5)$ \\
\hline Self & $4(14.8)$ \\
\hline Substance abuse & $3(11.1)$ \\
\hline HIV testing & $2(7.4)$ \\
\hline Residential drug & $1(3.7)$ \\
\hline Other community & $1(3.7)$ \\
\hline Pride center of WNY & $1(3.7)$ \\
\hline Intermediate care & $1(3.7)$ \\
\hline Other & $3(11.1)$ \\
\hline
\end{tabular}

SD, standard deviation; STD, sexually transmitted disease; WNY, Western New York (Erie, Niagara, Chautauqau \& Cattaragus counties).

of the respondents reported that they currently had a male sex partner $(n=14,51.9 \%)$. Almost all the participants had a history of substance abuse ( $n=26,96.3 \%)$. The majority of them reported that they had a permanent or a rental house $(n=20 ; 74 \%)$. However, most of them were uninsured $(n=20 ; 74 \%)$. With regard to HIV status, 2 of them were tested positive without 
an AIDS diagnosis, 16 of them were HIV negative with any number of self-reported HIV risks, and 8 of them were HIV negative without any self-reported HIV risk. There was only one participant with a known AIDS diagnosis. According to the collaborating organization protocol, all individuals who test positive are referred to an HIV care coordinator, are given confirmatory tests, and are connected to HIV services. The number of previous HIV tests before the current test ranged from 1 to 11 (mean $=3.1 ; \mathrm{SD}=2.6)$ and the number of STD tests ranged from 0 to $6($ mean $=1.4, \mathrm{SD}=1.9)$. In fact, many of them $(n=17 ; 63 \%)$ did not have any STD tests in the past year.

The mean and SD of HIV and STD testing among various subgroups are summarized in Table 2. Results indicated that the number of HIV and STD tests was greater for female participants than for male participants. Transgender individuals with a history of incarceration and being a sex worker had a higher number of HIV testing. Participants who were HIV positive without AIDS diagnosis had the highest number of HIV tests. Participants who had sex with males had more HIV and STD tests than those who only had sex with females. Black participants reported the highest number of both HIV and STD tests than other racial groups. Participants who self-selected for HIV and STD testing or were suggested by family or friends were found to have a higher number of HIV testing. Participants who had a permanent housing/rental situation or lived with family or friends had a higher number of HIV testing.

\section{Discussion}

In this study, we examined the associations among several demographic categories, sexual history, substance use, history of incarceration, ability to pay, HIV/STD testing history, support group membership, and HIV testing referral sources in a transgender sample. Very few studies have examined correlates of HIV testing in this population. Adding to the gap in evidence is the difficulty in accessing this and other marginalized population groups. This study extended our understanding of HIV testing in transgender individuals. Transgender individuals with some characteristics were found to have more HIV tests including female gender, black, HIV status (positive), a history of incarceration, sex worker, housing situation, and self-referral. We established that the motivation for HIV testing fell within the categories of HIV test accessibility and self-perceived HIV risk.
Table 2. Group Characteristics of HIV and STD Testing

\begin{tabular}{|c|c|c|}
\hline & $\begin{array}{l}\text { Number of } \\
\text { HIV Tests } \\
\text { Mean (SD) }\end{array}$ & $\begin{array}{l}\text { Number o } \\
\text { STD Tests } \\
\text { Mean (SD) }\end{array}$ \\
\hline \multicolumn{3}{|l|}{ Gender } \\
\hline Female $(n=23)$ & $3.48(2.68)$ & $1.65(2.04)$ \\
\hline Male $(n=4)$ & $1(0)$ & 0 \\
\hline \multicolumn{3}{|l|}{ Race } \\
\hline White $(n=11)$ & $1.81(1.60)$ & $0.55(1.21)$ \\
\hline Black $(n=8)$ & $4.75(3.06)$ & $3.00(2.07)$ \\
\hline Hispanic $(n=5)$ & $3.80(3.11)$ & $1.60(2.30)$ \\
\hline Unknown $(n=3)$ & $2.33(1.53)$ & $1.41(1.97)$ \\
\hline \multicolumn{3}{|l|}{ HIV status } \\
\hline Positive with an AIDS diagnosis $(n=1)$ & $3.00(-)$ & $5.00(-)$ \\
\hline Positive without an AIDS diagnosis $(n=2)$ & $6.00(1.41)$ & $4.00(1.41)$ \\
\hline Negative at risk $(n=16)$ & $3.75(2.84)$ & $1.56(1.93)$ \\
\hline Negative $(n=8)$ & $1.13(0.35)$ & 0 \\
\hline \multicolumn{3}{|l|}{ Sex partner } \\
\hline Nonspecific $(n=10)$ & $1.20(0.63)$ & $0.50(1.58)$ \\
\hline With male $(n=14)$ & $4.36(2.92)$ & $2.14(2.07)$ \\
\hline With female $(n=2)$ & $3.00(1.41)$ & 0 \\
\hline With both gender $(n=1)$ & $5(-)$ & $3(-)$ \\
\hline \multicolumn{3}{|l|}{ Incarcerated } \\
\hline Yes $(n=15)$ & $3.87(2.88)$ & $1.47(1.96)$ \\
\hline No $(n=12)$ & $2.17(1.99)$ & $1.33(2.06)$ \\
\hline \multicolumn{3}{|l|}{ Sex work } \\
\hline Yes $(n=15)$ & $3.87(2.88)$ & $1.47(1.96)$ \\
\hline No $(n=12)$ & $2.17(1.99)$ & $1.33(2.06)$ \\
\hline \multicolumn{3}{|l|}{ History of substance abuse } \\
\hline Yes $(n=26)$ & $3.16(2.6)$ & $1.27(1.87)$ \\
\hline No $(n=1)$ & $3(-)$ & $5(-)$ \\
\hline \multicolumn{3}{|l|}{ Insurance } \\
\hline Insured $(n=6)$ & $2.00(1.67)$ & $1.83(2.14)$ \\
\hline HIV uninsured program $(n=1)$ & $7(-)$ & $5(-)$ \\
\hline No $(n=20)$ & $3.25(2.73)$ & $1.10(1.80)$ \\
\hline \multicolumn{3}{|l|}{ Housing } \\
\hline Permanent housing/rental $(n=20)$ & $3.50(2.89)$ & $1.75(2.10)$ \\
\hline With family or friend $(n=2)$ & $3.50(0.71)$ & 0 \\
\hline Residential drug treatment $(n=3)$ & $1.33(0.58)$ & $1.73(1.00)$ \\
\hline Transitional housing $(n=1)$ & $2(-)$ & 0 \\
\hline Homeless in shelter $(n=1)$ & $1(-)$ & 0 \\
\hline \multicolumn{3}{|l|}{ Support group enrolled } \\
\hline Life changes $(n=13)$ & $4.46(2.79)$ & $2.15(1.91)$ \\
\hline Addiction awareness $(n=1)$ & $3(-)$ & $5(-)$ \\
\hline CDC voice $(n=6)$ & $1.67(1.21)$ & 0 \\
\hline HIV support group $(n=1)$ & $7(-)$ & $5(1)$ \\
\hline MANSEX $(n=6)$ & $1(0)$ & 0 \\
\hline \multicolumn{3}{|l|}{ Referral source } \\
\hline Evergreen $(n=6)$ & $1.83(1.60)$ & $0.50(1.22)$ \\
\hline Friend/family $(n=5)$ & $4.80(2.28)$ & $2.20(2.17)$ \\
\hline Self $(n=4)$ & $6.25(3.86)$ & $2.50(2.89)$ \\
\hline Substance abuse $(n=3)$ & $1.00(0)$ & 0 \\
\hline HIV testing $(n=2)$ & $4.00(1.41)$ & $1.50(2.12)$ \\
\hline Residential drug $(n=1)$ & $2(-)$ & $3(-)$ \\
\hline Other community $(n=1)$ & $4(-)$ & 0 \\
\hline Pride center of WNY $(n=1)$ & $1(-)$ & 0 \\
\hline Intermediate care $(n=1)$ & $3(-)$ & $5(1)$ \\
\hline Other $(n=3)$ & $1(-)$ & $1.00(1.73)$ \\
\hline
\end{tabular}

-, not applicable.

HIV test accessibility in this study is regarded as increased testing opportunities for transgender communities. Specific interventions that increase HIV testing rates are targeted outreach to specific populations or providing on-site HIV testing opportunities for residents of 
various housing types. Targeted HIV testing interventional efficacy has been successful ${ }^{23,24}$ and is found in this study through the association of HIV testing with gender and HIV testing with support group membership. The collaborating organization where HIV testing occurred sponsors a transgender health outreach program and provides a meeting space for various support groups. Although there is an association between gender identity and HIV testing, we feel that the standing evidence regarding higher HIV testing rates in cis women who are admitted in maternity wards $^{24}$ is not applicable to our population as none of the trans men in our sample reported a previous or current pregnancy. Similar to maternity ward HIV testing, substance abuse treatment centers and prison populations also have higher HIV testing rates. ${ }^{25,26}$ Study participants who reported an incarceration history were more likely to have HIV testing $(p<0.05)$.

Individuals who believe that they are at risk for HIV infection (self-risk perception) are found to have a higher number of HIV testing. Evidence also confirms that holding any level of HIV risk perception is a strong predictor of HIV testing. We found that HIV negative participants who perceived themselves to be at risk for infection had more than one HIV test in the past. Perceived greater sex partner risk was also associated with HIV testing, as was having a history of sex work (including exchanging sex for food, housing, or controlled substances). Our findings confirm that HIV testing can be increased by using self-perceived risk as a potential correlate for HIV testing. In addition, we found that targeted testing is successful and should be context specific. Being context specific means that HIV testing organizations also include resident-based testing opportunities, specifically jail facilities or live-in substance use rehabilitation facilities. One item that we feel is missing from current evidence but may increase HIV testing is the use of support groups as a strategy to access hard-toreach populations. Bringing the HIV test to the individual is not difficult as many outreach programs are already conducting the tests in environments such as mobile HIV testing in entertainment venues and health fairs. Although our study findings only indicate that transgender individuals with certain characteristics might have higher HIV tests, those characteristics may indicate the potential for increasing HIV testing to access marginalized population groups. As some of our participants have had an HIV test and already knew their status, it is unknown why they sought out additional HIV testing. Additional research on why repeat
HIV testing after a positive test notification occurs is needed and may hold key information regarding motivators to testing in hard-to-reach populations. Knowing one's HIV status is a foundational step of current treatment as a part of a prevention strategy.

\section{Limitations}

Limitations of this study include a small sample size that does not allow us the ability to perform a more rigorous statistical analyses. Therefore, inferences of our study findings are very limited and the results should be interpreted with caution. However, our findings provide preliminary information regarding potential characteristics in transgender individuals who had more HIV and STD tests and can be used to inform future research. In addition, we did not have information regarding the specific date the subjects came into the program, so it is possible that people came into the program during the late period of enrollment; their number of HIV and STD tests would be lower.

\section{Acknowledgment}

The study was funded by Patricia H. Garman Behavioral Health Nursing Endowment Fund at the University at Buffalo School of Nursing.

\section{Author Disclosure Statement}

No competing financial interests exist.

\section{References}

1. Costa $A B$, da Rosa Filho HT, Pase PF, et al. Healthcare needs of and access barriers for Brazilian transgender and gender diverse people. J Immigr Minor Health. 2016 [Epub ahead of print]; DOI: 10.1007/s10903016-0527-7.

2. Herbst JH, Jacobs ED, Finlayson TJ, et al. Estimating HIV prevalence and risk behaviors of transgender persons in the United States: a systematic review. AIDS Behav. 2008;12:1-17.

3. Institute of Medicine. The Health of Lesbian, Gay, Bisexual, and Transgender People: Building a Foundation for Better Understanding. Washington, DC: The National Academies Press, 2011.

4. Schulden JD, Song B, Barros A, et al. Rapid HIV testing in transgender communities by community-based organizations in three cities. Public Health Rep. 2008;123 Suppl 3(3_suppl):101-114.

5. Baral SD, Poteat T, Strömdahl S, et al. Worldwide burden of HIV in transgender women: a systematic review and meta-analysis. Lancet Infect Dis. 2013;13:214-222.

6. Operario D, Soma T, Underhill K. Sex work and HIV status among transgender women: systematic review and meta-analysis. J Acquir Immune Defic Syndr. 2008;48:97-103.

7. Catalano S. Stalking victims in the United States-Revised. Washington, DC: U.S. Department of Justice, 2012.

8. Baumbach JP, Foster LN, Mueller M, et al. Seroprevalence of select bloodborne pathogens and associated risk behaviors among injection drug users in the Paso del Norte region of the United States-Mexico border. Harm Reduct J. 2008;5:33.

9. Parsons JT, Halkitis PN. Sexual and drug-using practices of HIV-positive men who frequent public and commercial sex environments. AIDS Care. 2002;14:815-826.

10. Sanchez T, Finlayson T, Murrill $C$, et al. Risk behaviors and psychosocial stressors in the new york city house ball community: a comparison of 
men and transgender women who have sex with men. AIDS Behav. 2010;14:351-358.

11. Smallman S. The AIDS Pandemic in Latin America. Chapel Hill, NC: The University of North Carolina Press, 2007, pp. 113-163.

12. Institute of Medicine. Lesbian Health: Current Assessment and Directions for the Future. Washington: The National Academies Press, 1999.

13. Vega MY, Spieldenner AR, DeLeon D, et al. SOMOS: evaluation of an HIV prevention intervention for Latino gay men. Health Educ Res. 2011;26:407-418.

14. Vega MY, Spieldenner AR, Tang J. Sexo y le cuidad: sexual, ethnic and social identity intersections of Latino gay men in New York City. Calif J Health Promot. 2012;10:78-87.

15. Bockting WO, Miner MH, Swinburne Romine RE, et al. Stigma, mental health, and resilience in an online sample of the US transgender population. Am J Public Health. 2013;103:943-951.

16. Poteat $T$, Wirtz AL, Radix A, et al. HIV risk and preventive interventions in transgender women sex workers. Lancet. 2015;385:274-286.

17. Durand CM, Flexner C. HIV cure: knocking on the door. Clin Pharmacol Ther. 2013;93:382-384.

18. Hull MW, Montaner JS. HIV treatment as prevention: the key to an AIDSfree generation. J Food Drug Anal. 2013;21:S95-S101.

19. Gwadz M, Cleland CM, Leonard NR, et al. Hybrid STTR intervention for heterosexuals using anonymous HIV testing and confidential linkage to care: a single arm exploratory trial using respondent-driven sampling. BMC Public Health. 2015;15:1133.

20. Gwadz M, Cleland CM, Hagan $\mathrm{H}$, et al. Strategies to uncover undiagnosed HIV infection among heterosexuals at high risk and link them to HIV care with high retention: a "seek, test, treat, and retain" study. BMC Public Health. 2015;15:481.

21. Logie $\mathrm{CH}$, Lacombe-Duncan $\mathrm{A}$, Wang $\mathrm{Y}$, et al. Prevalence and correlates of HIV infection and HIV testing among transgender women in Jamaica. AIDS Patient Care STDS. 2016;30:416-424.
22. Gage AJ, Ali D. Factors associated with self-reported HIV testing among men in Uganda. AIDS Care. 2005;17:153-165.

23. Holtgrave DR. Costs and consequences of the US Centers for Disease Control and Prevention's recommendations for opt-out HIV testing. PLoS Med. 2007;4:e194.

24. Maman S, King E. Changes in HIV testing policies and the implications for women. J Midwifery Womens Health. 2008;53:195-201.

25. Rosen DL, Wohl DA, Golin CE, et al. Comparing HIV case detection in prison during opt-in vs. opt-out testing policies. J Acquir Immune Defic Syndr. 2016;71:e85-e88.

26. Rowell-Cunsolo TL, El-Bassel N, Hart CL. Black Americans and incarceration: a neglected public health opportunity for HIV risk reduction. J Health Care Poor Underserved. 2016;27:114-130.

Cite this article as: Juarez-Cuellar A, Chang YP (2017), HIV testing in urban transgender individuals: a descriptive study, Transgender Health 2:1, 151-155, DOI: 10.1089/trgh.2016.0047.

\section{Abbreviations Used}

AIRS $=$ New York State AIDS Institute Reporting System $\mathrm{SD}=$ standard deviation

$\mathrm{STD}=$ sexually transmitted disease $\mathrm{STTR}=$ seek, test, treat, and retain

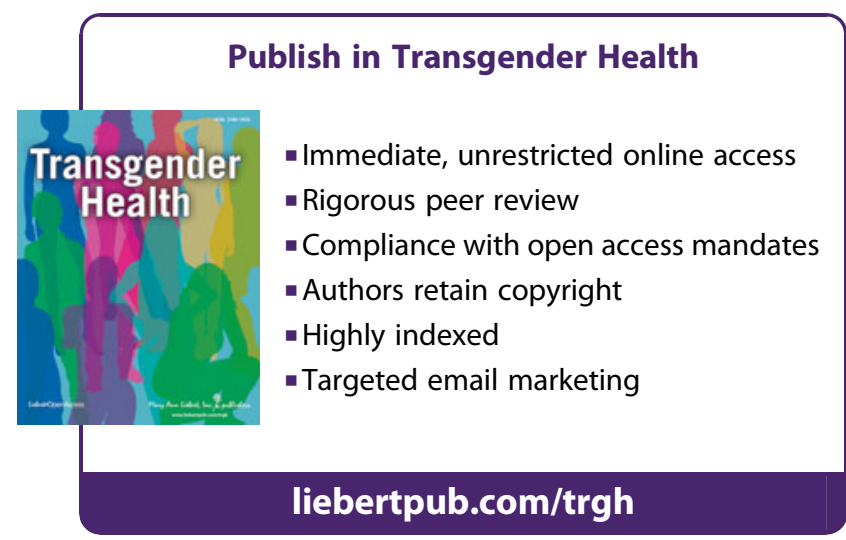

